\title{
Rodolphe Töppfer, Correspondance complète, t. VI, 23 novembre 1841-23 juin 1843
}

\section{Lise Sabourin}

\section{(2) OpenEdition}

1 Journals

\section{Édition électronique}

URL : http://journals.openedition.org/studifrancesi/4398

DOI : 10.4000/studifrancesi.4398

ISSN : 2427-5856

Éditeur

Rosenberg \& Sellier

\section{Édition imprimée}

Date de publication : 1 septembre 2016

Pagination : 342

ISSN : 0039-2944

\section{Référence électronique}

Lise Sabourin, «Rodolphe Töppfer, Correspondance complète, t. VI, 23 novembre 1841-23 juin 1843 », Studi Francesi [En ligne], 179 (LX | II) | 2016, mis en ligne le 01 septembre 2016, consulté le 18 septembre 2020. URL : http://journals.openedition.org/studifrancesi/4398 ; DOI : https://doi.org/ 10.4000/studifrancesi.4398

Ce document a été généré automatiquement le 18 septembre 2020.

\section{(c)}

Studi Francesi è distribuita con Licenza Creative Commons Attribuzione - Non commerciale - Non opere derivate 4.0 Internazionale. 


\title{
Rodolphe Töppfer, Correspondance complète, $\mathrm{t}$. VI, 23 novembre 1841-23 juin 1843
}

\author{
Lise Sabourin
}

\section{RÉFÉRENCE}

RODOLPHE TÖPPFER, Correspondance complète, éditée et annotée par Jacques Droin, avec le concours de Danielle Buyssens et de Jean-Daniel Candaux, t. VI, 23 novembre 1841-23 juin 1843, Genève, Droz, 2013, 405 pp.

1 La publication de la Correspondance de Rodolphe Töppfer, ce fils de peintre devenu écrivain voyageur, si lié à la culture française, se poursuit, avec ce tome VI, contenant les lettres de novembre 1841 à juin 1843, qui correspond à l'agitation politique en Suisse menant à organiser une Constituante pour refondre le système politique qui avait pourtant assuré «27 années de bonheur» à Genève. Le professeur d'esthétique s'engage de ce fait, à l'appel de son ami Auguste de la Rive, dans le journalisme conservateur qui convient à ses idées face à des événements tournant à la guerre civile, moins à son tempérament d'artiste et à sa santé vacillante.

2 Ce volume offre donc une bonne connaissance des points de vue contrastés de la politique genevoise, par la préparation des articles parus dans le «Courrier de Genève» contre le radical James Fazy, mais aussi de l'élaboration progressive des fameux Voyages en zigzag (parus dans la presse à partir du 15 juin 1843, puis en volume en 1844) qui firent la renommée du flâneur amoureux rousseauiste de la nature. En effet, l'éloignement d'avec son éditeur, le cousin parisien Jacques-Julien Dubochet, suscite moult échanges de lettres précisant les modes d'illustration, les formats, les collaborations de dessinateurs et graveurs: renseignements évidemment fructueux chez un auteur qui faillit être lui-même peintre et maîtrise les savoirs techniques comme artistiques. 
3 Simultanément Töppfer rédige son Voyage à Venise en 1841 et ses Essais d'autographie, avant d'effectuer, avec les élèves du pensionnat qu'il avait créé, son dernier périple pédagogique en août-septembre 1842, qui donnera naissance au Voyage autour du MontBlanc.

4 Les relations amicales (avec David Munier, Alexandre Vinet, Xavier de Maistre) et familiales (notamment avec sa femme Kitty lors du deuil de sa belle-mère Jeanne Moulinié-Duruz) suscitent d'assez longues lettres, annotées avec précision par les éditeurs critiques, qui fournissent aussi en annexes des articles de journaux éclairant la situation fédérale helvète, avant les habituels index des œuvres, personnes et tables des lettres. 